\title{
Publisher Correction: Photocatalysis as the 'master switch' of photomorphogenesis in early plant development
}

Derren J. Heyes (1), Shaowei Zhang, Aoife Taylor, Linus O. Johannissen, Samantha J. O. Hardman (1), Sam Hay and Nigel S. Scrutton (1D

Correction to: Nature Plants https://doi.org/10.1038/s41477-021-00866-5, published online 8 March 2021.

In Fig. 4 of this Review originally published, a delta symbol was mistakenly added to the structure of NADP ${ }^{+}$. This error has now been corrected.

Published online: 9 April 2021

https://doi.org/10.1038/s41477-021-00911-3

() Springer Nature Limited 2021 